\title{
The recurrent primary retroperitoneal liposarcoma
}

\author{
Nagy $\mathrm{V}^{1}$, Bober $\mathrm{J}^{2}$, Zavacky $\mathrm{P}^{2}$, Brandebur Jr O², Svajdler $\mathrm{M}^{3}$ \\ Department of Urology, PJ Safarikiensis University, Medical Faculty and L Pasteur University Hospital, \\ Kosice, Slovakia. vincent.nagy@upjs.sk
}

\begin{abstract}
Aim: Describe a patient with multiple recurrences of the primary recurrent liposarcoma.
Clinical case: A 60-years-old man complained of weight loss (BMI 18.4) with a palpable huge retroperitoneal tumour, which displaced left kidney, and was confirmed on USG and CT. Laboratory examination showed anaemia and pathological blood tests. Chest X-ray initially showed a negative finding. A complete transperitonealy surgical extirpation of the tumour with left side nephrectomy was performed on June 28, 2007. The tumour mass weight was $1900 \mathrm{~g}$. It was lying on the posterior face of the kidney in diameters $170 \times 120 \times 120 \mathrm{~mm}$, completely capsulated by thin grey-pink capsula with peripheral fat tissue on the section grey-pink, lobulary shaped, in $3 / 4$ parts with central necrotic changes. Histopathologically was confirmed the primary dedifferentiated (non-lipogenous) liposarcoma low grade of malignancy. Nephrectomy specimen was confirmed as age related finding. There was no evidence of positives surgical margins. Despite oncological and surgical treatment, followed repeated recurrence with eight transperitoneal surgeries in the retroperitoneum and abdomen with extirpation of the metastases, left side hemicolectomy, splenectomy and repeated extirpation tumour metastases from abdomen and radix mesenterii. Last tumour weighed 2900 grams. Patient died on January 9, 2011, after the eight surgeries on multiorgans failure due to hemorrhagic shock and persistent atrial fibrilaton by cardiopulmonary insufficiency. As a speciality, he was treated without transfusion because as Jehovah's witness he refused blood derivates. Conclusion: Despite complex surgical and oncological treatment, the prognosis in patient with recurrent liposarcoma was fatal (Tab. 1, Fig. 5, Ref. 50). Full Text in PDF www.elis.sk.

Key words: primary retroperitoneal liposarcoma, recurrence, surgery, chemotherapy.
\end{abstract}

Retroperitoneal liposarcoma is an infrequent locally aggressive and recurrent malignancy developed from mesenchymal tissue. We report a seldom case of a huge primary retroperitoneal liposarcoma on the left side, which invaded and displaced the left kidney with multicentric intraperitoneal and retroperitoneal repeated recurrences, adjuvant chemotherapy and eight surgeries.

\section{Case presentation}

The 60-years old man complained of weight loss $10 \mathrm{~kg}$ in three month (weight $52 \mathrm{~kg}$, hight $168 \mathrm{~cm}$, BMI: 18.4) with some vague symptoms. Physical examination revealed a palpable abdominal mass on the left side. Preoperative USG and CT imaging study showed a huge retroperitoneal tumour. On USG examination, there was seen a clear burdened hypoechoic retroperitoneal mass. CT on June 20, 2007 demonstrated on the left side retroperitoneal tumour $167 \times 124 \times 119 \mathrm{~mm}$, a slightly heterogenous mass with native density +22 to $+31 \mathrm{HU}$, and postcontrast enhancement from +29 to

${ }^{1}$ Department of Urology, PJ Safarikiensis University, Medical Faculty and L Pasteur University Hospital, Kosice, Slovakia, ${ }^{2}$ st Department of Surgery, PJ Safarikiensis University, Medical Faculty and L Pasteur University Hospital, Kosice, Slovakia, and ${ }^{3}$ Department of Pathology, L Pasteur University Hospital, Kosice, Slovakia

Address for correspondence: V. Nagy, MD, PhD, Department of Urology, PJ Safarikiensis University, Medical Faculty and L Pasteur University Hospital Kosice, SNP 1, SK-40 11 Kosice, Slovakia.

Phone: +421.55.6403589, Fax: +421.55.6403603
+58 and +60 HU. Tumour invaded and displaced the left kidney without hydronephrosis (Fig. 1). Laboratory data showed anaemia and pathological blood tests (Hb11,5 dg/l, RBC 3,91x10 12/1, PVC 0,34, WBC 15,6x10 $/ 1, \operatorname{Tr} 426000$, N 87\% seg, Eo 2\%, Mo 3\%, Ly 8\%, elevated Fibrinogen 8,55 (N 1.8-3.5 g/l), FW 88/first hour). $\mathrm{S}-\mathrm{Na} 140 \mathrm{mmol} / \mathrm{l}, \mathrm{S}-\mathrm{K}$ 4,0 mmol/1, S-Cl $104 \mathrm{mmol} / \mathrm{l}$, S-Creatinine $52,3 \mu \mathrm{mol} / 1$, GMT 0,64, ALP 2,87, PSA $1,01 \mathrm{ng} / \mathrm{ml}$ were within normal limits. Chest X-ray showed initially a negative finding without metastasis (MTS). A complete transperitonealy surgical extirpation of the tumour with left side nephrectomy without adrenalectomy was performed on June 28, 2007. The tumour mass weighted $1900 \mathrm{~g}$. Macroscopically the tumour was lying on the posterior face of the kidney with diameters 170x120x120 mm and was completely capsulated by thin grey-pink capsula with peripheral fat tissue (Fig. 2). On the section, the tumour was grey-pink, lobulary shaped, in $3 / 4$ parts with central necrotic changes. Histopathologically, tumour was confirmed as dedifferentiated liposarcoma (non-lipogenous) low grade of malignancy; nephrectomy specimen was histologically confirmed as age related finding. There was no evidence of positive surgical margins. After oncologist consultation, he received postoperatively no adjuvant therapy. CT three months later on October 3, 2007 showed no MTS. February 11, 2008 on haematology examination was established diagnosis of heterozygous MTHFR congenital thrombophilia without elevation homocystein acids, hyperuricemia, hepatopathia wits elevation ALP, deficiency of vitamin K depending factors and Factor VIII, and sideropenia. On February 20, 2008, eight months later, CT 

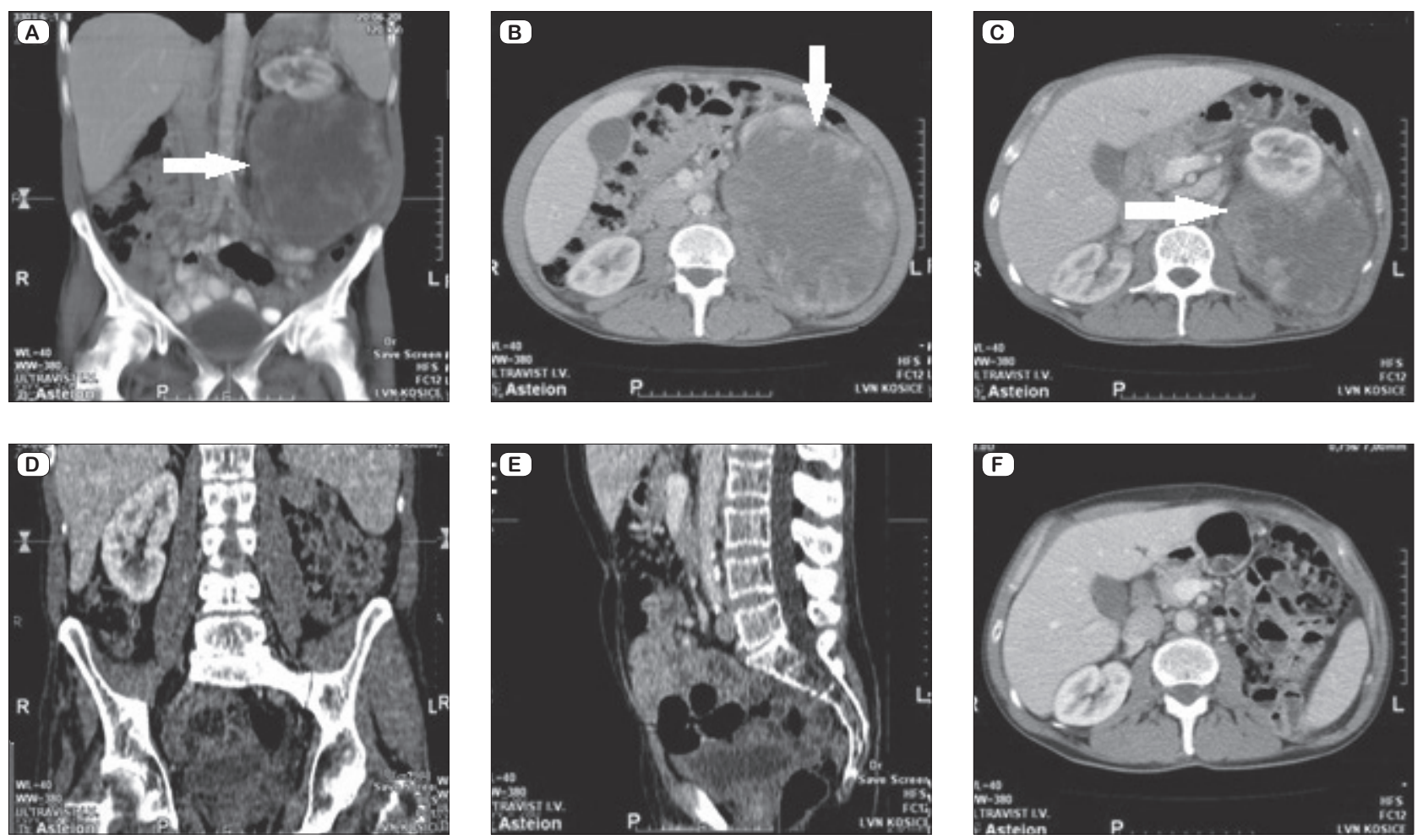

Fig. 1. Preoperative CT with a huge retroperitoneal tumour (arrows) invading the left kidney (A-C). Postoperative CT after first surgery with nephrectomy showed no tumour (D-F).

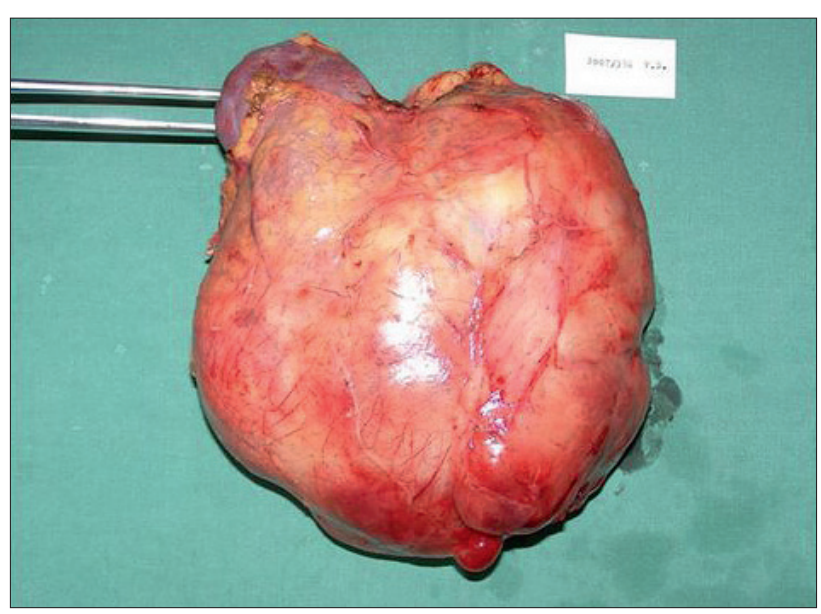

Fig. 2. Operative preparaion - encapsulated retroperitoneal tumour with the left kidney (tweezers).

confirmed first retroperitoneal MTS on the left side which were resected on March 7, 2008 (Fig. 3). Similarly, CT on October 10, 2008 showed recurrence of a new MTS nearby m. psoas and colon descendens. Followed extirpation of this tumour on October 28, 2008. On November 2, 2009 due to new MTS, left hemicolectomy with tumour extirpation was done. Because recurrence of the liposarcoma continued, the surgical treatment was performed on March 3, 2010. During this surgery, multiplices MTS were found on radix mesenterii and also completely extirpated (Fig. 4). Followed operations on April 8, 2010, then on June 15, 2010, and fi-
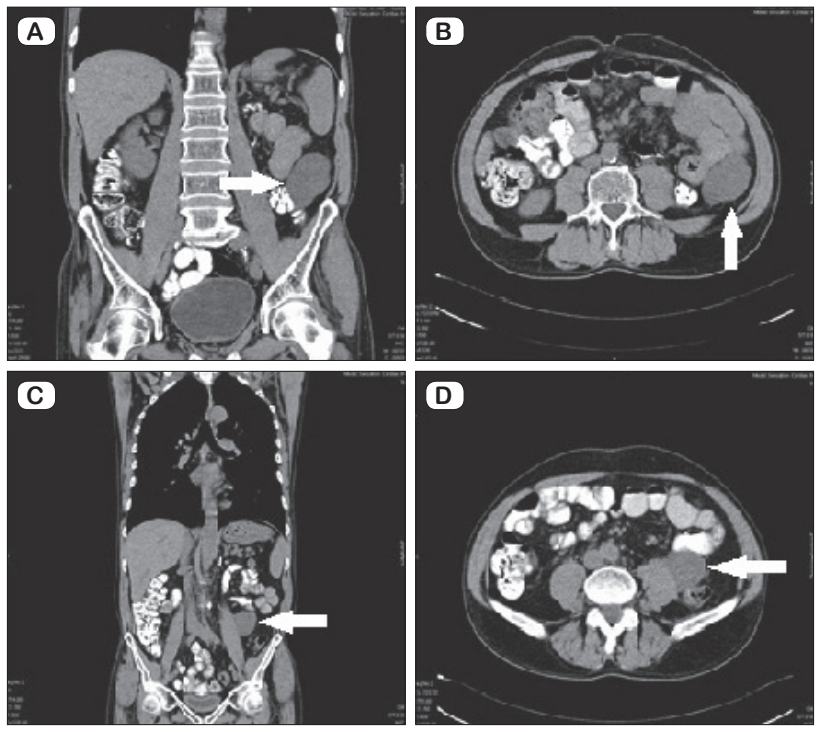

Fig. 3. Tumour recurrences (arrows) on CT imaging on February 20, 2008 (A-B), and on October 10, 2008 (C-D).

nally on December 28, 2010 because of excessive huge recurrence in the whole left part of the abdoment and retroperitoneum with tumour weight 2900 grams (Fig. 5). The position of this metastasis was the same as the first time surgical resected tumour in year 2007. Patient died on January 9, 2011, after the eight surgeries on multiorgans failure due to hemorrhagic shock and persistent atrial fibrilaton and cardiopulmonary insufficiency. As a speciality, he 

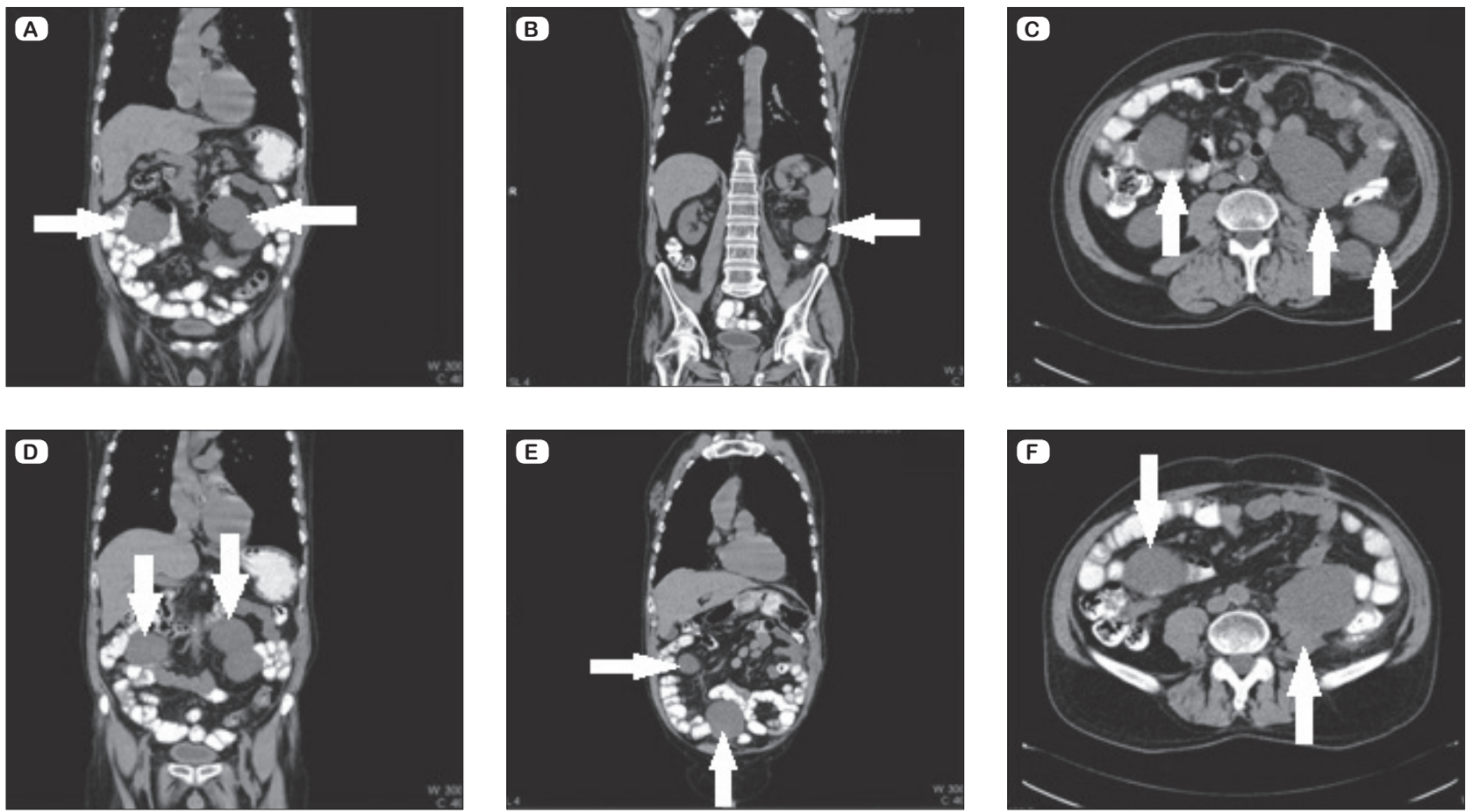

Fig. 4. Repeated recurrency of the liposarcomas on CT imaging on February 22, 2010.
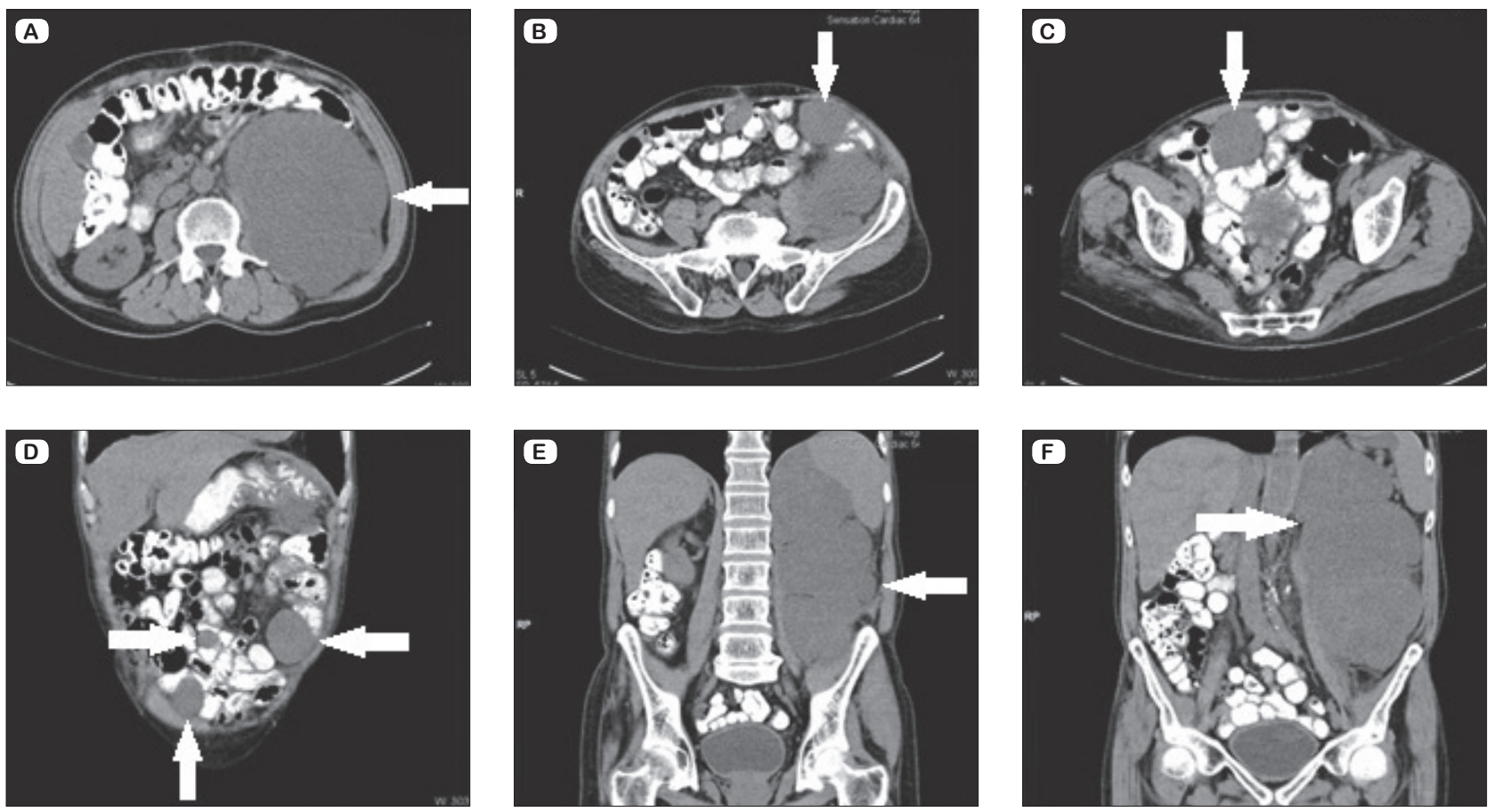

Fig. 5. Huge retroperitoneal metastases on CT on December 10, 2010.

was treated without transfusion because as Jehovah's witness refused blood derivates. On May 2008, started well tolerated firstline oncological adjuvant chemotherapy only by sole application of Adriblastina (adriamycine) $100 \mathrm{mg}$ to eight cycles to September 2008 due to solitary kidney and restricted calculated GFR 0,810, and renal TRR 0,966. Bone scan on September 2008 was nega- tive, without MTS. Control PET/18 FDG on April 4, 2008 found some small deposits in mediastinum, pulmonary hilum and right supraclavicular region. Similarly, suspect finding was found in skeleton nearby joints without evidence of metabolic metastatic activity. Because of the malignancy continued in recurrence from November 29, 2008 to May 31, 2009, the second-line of the che- 
Tab. 1. List of the operations and hospitalisations.

\begin{tabular}{|c|c|}
\hline - 28.6.2007 & $\begin{array}{l}\text { Transperitoneal extirpation of the retroperitoneal tumour } \\
\text { with left side nephrectomy, the weight of extirpated speci- } \\
\text { men was } 1900 \text { grams }\end{array}$ \\
\hline • 7.3.2008 & Relaparotomy, extirpation of the retroperitoneral MTS \\
\hline$\cdot 28.10 .2008$ & Relaparotomy, extirpation of the paracolic MTS \\
\hline$\cdot 4.11 .2009$ & $\begin{array}{l}\text { Relaparotomy, revisio, extirpatio MTS in toto, hemicolec- } \\
\text { tomy on the left side, extirpatio MTS from scar }\end{array}$ \\
\hline$\cdot 3.3 .2010$ & $\begin{array}{l}\text { Laparotomy, extirpatio retroperitoneal multiplices MTS } \\
\text { and from radix mesenterii }\end{array}$ \\
\hline - 8.4 .2010 & Extraperitoneal MTS extirpation in toto \\
\hline$\cdot 15.6 .2010$ & $\begin{array}{l}\text { Relaparotomy, extirpatio MTS multiplices e retroperitonei } \\
\text { 1. sin. et radicis mesenterii. }\end{array}$ \\
\hline -9.-12.7.2010 & $\begin{array}{l}\text { Hospitalisation due to subileous status only with infusion } \\
\text { therapy. }\end{array}$ \\
\hline -28.12.2010 & $\begin{array}{l}\text { Extirpatio MTS retroperitonei et radicis mesenterii mul- } \\
\text { tiplices, splenectomy, with tumour weight } 2900 \text { grams }\end{array}$ \\
\hline
\end{tabular}

motherapy was applied. The patient has taken sole nine cycles of Ifosfamid (Holoxan $8000 \mathrm{mg}$, Uromitexan $8000 \mathrm{mg}$ ). Because recurence after repeated surgery continued, on June 2009 started the third-line of chemotherapy by application of Dacarbazin 1800 $\mathrm{mg}$ as monotherapy. Despite intensive oncological third-line chemotherapy, the patient underwent after an initial operation due to recurrent malignancy totally seven surgeries (Tab. 1) (see list of the operations). Finally, totally thirteen CT studies were performed. CT confirmed osteolytic pelvic and pulmonary metastases. Histopathological examination of the recurrent tumour recurrence operated on June 6, 2010 revealed spindle-cell proliferation set in a variable dense fibrous, collagenous and myxoid stromal tissue with sporadic mixture of the atypical hyperchromatous scattered multinuclear cells with sporadic mitotic activity without lipogenous component. Histological examination confirmed a relapse of the well-differentiated liposarcoma, spindle cell variant and low grade liposarcoma dedifferentiation.

\section{Discussion}

With their embryological origin in the mesoderm and in nerve structures of the neuroectodermic layer soft tissue, sarcomas represent only $1.5 \%$ cases in the National Registry of Malignant Tumours in Mexico (Pérez-Ponce et al, 2008). Liposarcoma is a malignancy of fat cells and is the most frequent soft tissue sarcoma localized in the retroperitoneum often with multicentric origin (Sato et al, 2004). Retroperitoneal sarcoma is a rare tumour that accounts for $10-15 \%$ of soft tissue malignancies. The incidence is 2.5 per million and liposarcoma accounts for approximately $20 \%$ of all retroperitoneal sarcomas. As a slow-growing tumour with vague symptoms, the most frequent symptom is nonspecific abdominal pain, sometimes anorexia, loss weight and diffuse abdominal enlargement, but rarely it was presented by another symptoms, e.g. lower gastrointestinal bleeding or hemoperitoneum, with a picture of acute abdomen resulting from a massive tumour haemorrhage (Wanchik et Lucha, 2009; Echenique -Elizondo et Amondarain-Arratibel, 2005; Choi et al, 2010; Guzmán Martínez-Valls et al, 1996). Sometimes primary liposarcoma can arise from the renal capsule (Terakawa et al, 2005), and mesenterium (Moyana, 1988). Rare exists synchronous primary large Bcell gastric lymphoma and huge retroperitoneal liposarcoma with inguinal hernia (Ghimire et al, 2011), retroperitoneal liposarcoma extending into the thigh (Salemis et al, 2011), retroperitoneal liposarcoma invading an abdominal aortic aneurysm causing rupture (Paravastu et al.2010), paraneoplastic retinopathy (Kondo et al, 2010), or tumour presenting as an incarcerated femoral hernia (Bognár et al, 2009). Sometimes a suspect huge preoperative diagnosed retroperitoneal liposarcoma can be commute for adrenal or retroperitoneal myelolipoma (Nishio et al, 2007; Takahashi et al, 2004). Retroperitoineal liposarcoma can occur with reactive pleural effusion (Funahashi et al, 2004), or well-differentiated liposarcoma of the retroperitoneum and spermatic cord, contiguous through the inguinal canal was presented clinically as a scrotal mass (Longbotham and Joyce, 1987). In literature are reported extremely rare cases of paraneoplastic syndromes or ectopic production of proteins associated with liposarcoma, as a production of Granulocyte-Colony Stimulating Factor, alpha-fetoprotein, paraneoplastic pemphigus and leucocytosis, Acrokeratosis paraneoplastica (Bazex's syndrome) or cases of retroperitoneal liposarcoma associated with small plaque parapsoriasis (Tartaglia et al, 2007). Liposarcoma can occur in the extremities with unusual pattern of metastatic spread (Vassilopoulos et al, 2001).

If we used the words ,abdominal and retroperitoneal liposarcoma" for searching in Pubmed, we have found more than 70 articles with this topic from 1954 to June 22, 2011. Many of them described a case report or small series on a huge retroperitoneal or abdominal liposarcoma in both, men and women. In some cases, tumour mass occupies the whole retroperitoneum, pelvis and part of the abdomen. Sometimes can reach substantial proportions (Hann et al, 2010; Echenique-Elizondo and Amondarain-Arratíbel, 2005; Maámouri et al, 2005; Pascual Samaniego et al, 2003;Antinori et al, 2002; Farese and Palasciano, 2002; Azpiazu Arnaiz et al, 2000). Removal of a huge retroperitoneal or abdominal mass, sometimes with concomitant resection of adjacent organs were needed, but half of the patients developed tumour recurrence, mainly limited to the retroperitoneum or abdominal cavity. The mean recurrence-free survival was 43.3 months, with 3 and 5-year overall survival rates of $79 \%$ and $61 \%$, respectively (Fernández- Ruiz et al, 2010). At surgery, pelvic and abdominal organs were displaced and liposarcomas invaded surrounding organs as uterus, adnexa (Smrkolj et al, 2010; Susini et al, 2000), mesenterium, small intestine or colon (Choi et al, 2010) etc. including the right or left kidney, in which cases hemicolectomy, and nephrectomy as in our patient were performed. The resected weight of the tumour reached from some decagrammes, but more frequently nearby from 1000-2000 grams, or some kilograms, sometimes 5.5-6 kg (Izumi et al, 2010; Ebbe, 1993), $15 \mathrm{~kg}$ (Tsang et al, 2003) an extremely large liposarcoma weighted $18 \mathrm{~kg}$ (Inoue et al, 2005), and $29 \mathrm{~kg}$ (Hsiao et al, 1998).

As the first preoperative imaging study, except history and physical examination, was used USG, sometimes with incidentally founding of the liposarcoma, but the best diagnostic tool before surgery in decisive majority was mainly CT, or MRI, with histological confirmation during or after surgery (Shoji et al, 2009; Takahashi 
et al, 2009; Song et al, 2007; Funahashi et al, 2006; Kurosaki et al, 1998; Guzmán Martínez-Valls et al, 1997; Dieckmann et al, 1997).

The histological subtype and margins of resection are the most important prognostic factors for survival in primary retroperitoneal liposarcoma. Sato et al (1999) described nine primary intra-abdominal or retroperitoneal liposarcoma, of which eight were recurrent tumours. Histopathological examination of primary tumours revealed that the number of well-differentiated, pleomorphic and myxoid type was two, four and three respectively. In two recurrent cases, histological differentiation changed from well-differentiated type into myxoid or pleomorphic types. It was seen also by other authors. Spindle cell liposarcoma is presently regarded as a rare variant of well-differentiated liposarcoma, which has the potential for aggressive clinical behaviour (Shioi et al. 2010). Dedifferentiated histological subtype and the need for contiguous organ resection was associated with an increase risk of local and distant recurrence. Nephrectomy may be needed to achieve complete resection, but has no influence on disease specific survival. Singer et al (2003) in a prospective database identified 177 patients with primary liposarcoma operated on for curative intent. Of them 99 (56\%) presented with well-differentiated, 65 (37\%) with dedifferentiated, 9 (5\%) with myxoid, and 4 (2\%) with round cell morphology. Multivariate analysis showed that dedifferentiated liposarcoma subtype was associated with a 6-fold increased risk of death compared with well-differentiated histology $(p<0.0001)$. In addition to histological subtype, incomplete resection $(\mathrm{p}<0.0001)$, contiguous organ resection (excluding nephrectomy; $p=0.05$ ), and age $(\mathrm{p}=0.03)$ were important independent prognostic factors for survival in retroperitoneal liposarcoma.

The only accepted treatment is a wide surgical excision with clear margins, without a clear benefit for adjuvant treatment. The very uncommon nature of these tumours and their varied histopathology, site and behaviour classify them as a difficult entity in terms of treatment (Pérez-Ponce et al, 2008). Since neoadjuvant and adjuvant therapy as well as intraoperative radiotherapy failed to prove prognostic value, curative resection remains the main treatment for primary and recurrent liposarcomas (Niedergethmann et al, 2001). The main problem after surgery is local or distant recurrence. Local recurrences are frequent, especially in the first three years, often in the absence of distant metastases. Farma et al (2003) in 4 patients for retroperitoneal liposarcoma performed 15 operations, in 4 patients a second operation was performed for recurrence, in 3 a third operation and in 1 a fourth. Fotiadis et al (2000) described two patients in whose tumour recurred 5 times. In our patient, we have done eight surgeries. When the tumour recurs locally, the best therapy is still to remove the mass. In the treatment of liposarcoma the conventional chemotherapy does not seem effective, while radiotherapy has a little improvement on survival. Generally, the prognosis was poor with overall 5-year survival of $15-50 \%$ (Lauretti et al, 1998). Yoshida et al (2007) in a 58-year-old woman after resection of giant retroperitoneal liposarcoma and the transverse colon, spleen, and the left kidney with disease recurrence initially unsuccessfully used mesna, doxorubicin, ifosfamide, and dacarbazine therapy (MAID). Despite this chemotherapy disease progressed, and patient developed oedema in the bilateral legs due to inferior vena cava (IVC) compression. Then they started weekly paclitaxel therapy $\left(100 \mathrm{mg} / \mathrm{m}^{2}\right)$, once a week for 3 weeks followed by 1 drug-free week. CT revealed no change as the result of chemotherapy; however, IVC compression had improved, and leg oedema had decreased. She died 11 month later after starting paclitaxel therapy. Yokoi et al (2009) in a 53-year-old patient after surgery with multiple unresectable abdominal metastases histologically proven as dedifferentiated, and well-differentiated liposarcoma unsuccessfully used as a first-line VAC (VCR $1.5 \mathrm{mg}$, ACD $0.5 \mathrm{mg}$, CPA $900 \mathrm{mg}$ ) chemotherapy with disease progression. As second-line chemotherapy, weekly IFM (2g)+CDDP (30 mg) was given. A partial response against peritoneal dissemination was achieved. However, hepatic metastases increased, and the patient died 6 months after surgery. They concluded, that this case suggested that IFM+CDDP might be useful in dedifferentiated liposarcoma. Baratti et al (2010) assessed the outcome of clinically and pathologically homogenous subsets of 37 patients with peritoneal sarcomatosis, from which 13 patients had retroperitoneal liposarcoma (RPLP), uniformly treated by cytoreductive surgery (CRS) and hyperthermic intraperitoneal chemotherapy (HIPEC) with cisplatin and doxorubicin or mitomycin-C. Overall, the results of CRS and HIPEC did not compare favorably to those of conventional therapy. In a subgroup analysis, the combined approach did not change RPLP natural history. In our patient, the progression of the malignant diseases continued despite third-line chemotherapy, and patient developed new metastases.

Also, our case showed multiple recurrences and surgeries and unsuccessful adjuvant chemotherapy with limited survival. As review of literature showed, curative resection remains the main treatment for primary and recurrent liposarcomas. No standardized guidelines have been established for its treatment because too small series of the patients have been reported and surgical resection was considered by all authors as the treatment of choice. Some success on the field of the adjuvant chemotherapy must be proven by well controlled, blinded, randomized studies.

\section{Conclusion}

Primary retroperitoneal liposarcoma is a serious malignancy without standardized treatment. This diseases to prejudice QoL because multiple surgeries and unsuccessful adjuvant therapy with unpleasant consequences for patients. Curative resections remains the main treatment for primary and recurrent liposarcomas, and the best therapy is still to remove the mass. Surgical treatment of the primary recurrent liposarcoma without effective adjuvant oncological therapy had limited effectivity.

\section{References}

1. Pérez-Ponce Y, Castellanos-Alejandre R, Guerrero-Romero JF et al. Retroperitoneal liposarcoma as etiology of abdominal pain. Case report and literature review. Cir Cir 2008; 76 (1): 77-82.

2. Sato H, Minei S, Sugimoto S et al. Multicentric liposarcoma. Int J Urol 2004; 11 (12): 1133-1135. 
3. Wanchik K, Lucha P. Dedifferentiated retroperitoneal liposarcoma presenting as lower gastrointestinal bleeding, a case report and review of the literature. Mil Med 2009; 174 (3): 328-330.

4. Echenique-Elizondo M, Amondarain-Arratibel JA. Giant retroperitoneal liposarcoma. Cir Esp 2005; 77 (5): 293-295.

5. Choi YY, Kim YJ, Jin SY. Primary liposarcoma of the ascending colon: a rare case of mixed type presenting as hemoperitoneum combined with other type of retroperitoneal liposarcoma. BMC Cancer 2010; 27 (10): 239.

6. Guzmán Martínez-Valls PL, Ferrero Doria R, López Alba J et al. Intratumour and retroperitoneal massive hemorrhage caused by retroperitoneal liposarcoma. Actas Urol Esp 1996; 20 (8): 754-756.

7. Terakawa T, Taguchi I, Imanishi O, Yamanaka N. A case of retroperitoneal liposarcoma arising from the renal capsule. Hinyokika Kiyo 2005; 51 (3): 171-173.

8. Moyana TN. Primary mesenteric liposarcoma. Am J Gastroenterol 1988; 83 (1): 89-92.

9. Ghimire P, Wu GY, Zhu L. Rare synchronous primary large B-cell gastric lymphoma and huge retroperitoneal liposarcoma with inguinal hernia in chronic hepatitis B patient. Curr Oncol 2011; 18 (2): e103-108.

10. Salemis NS, Nisotakis K, Patouras $P$ et al. Retroperitoneal liposarcoma extending into the thigh. Am J Surg 2011; 201 (5): e38-40.

11. Paravastu SC, Ghosh J, Farquharson FG, Walker MG. Rupture of an abdominal aortic aneurysm post EVAR: a rare presentation of retroperitoneal liposarcoma. Vasc Endovascular Surg 2010; 44 (6): 494-498.

12. Kondo M, Mokuno K, Uemura A et al. Paraneoplastic retinopathy associated with retroperitoneal liposarcoma. Clin Ophthalmol 2010; 26 (4): 243-245.

13. Bognár G, Bereczky B, Barabás L et al. Reccurrent retroperitoneal liposarcoma presenting as an incarcerated femoral hernia. Magy Seb 2009; 62 (1): 30-33.

14. Nishio K, Tokiwa $\mathbf{S}$, Saito $\mathbf{K}$ et al. A case of a giant adrenal myelolipoma in a man with spinal cord injury. Hinyokika Kiyo 2007; 53 (6): 387-391.

15. Takahashi Y, Imamura T, Irie $\mathbf{H}$ et al. Myolipoma of the retroperitoneum. Pathol Int 2004; 54 (6): 460-463

16. Funahashi M, Makiyama K, Sugiura S et al. Retroperitoneal liposarcoma with reactive pleural effusion: a case report. Hinyokika Kiyo 2004; 50 (2): 115-117.

17. Longbotham JH, Joyce RP. Retroperitoneal liposarcoma presenting as spermatic cord tumour.Urology 1987; 30 (3): 276-280.

18. Tartaglia F, Blasi S, Sgueglia $\mathbf{M}$ et al. Retroperitoneal liposarcoma associated with small plaque parapsoriasis. World J Surg Oncol 2007; 9 (5): 76.

19. Vassilopoulos PP, Voros DN, Kelessis NG et al. Unusual spread of liposarcoma. Anticancer Res 200121 (2B): 1419-1421.

20. Hann HH, Choi KH, Kim DS et al. Retroperitoneal giant liposarcoma. Korean J Urol 2010; 51 (8): 579-582.

21. Maámouri N, Cheikh I, Ouerghi $\mathbf{H}$ et al. Giant retroperitoneal liposarcoma. One case report. Rev Med Interne 2005; 26 (2): 145-148.

22. Pascual Samaniego M, Gonzáles Fajardo JA, Fernández de la Gándara F et al. Giant retroperitoneal liposarcoma. Actas Urol Esp 2003; 27 (8): 640-644.

23. Antinori A, Antonacci V, Magistrelli P. Giant retroperitoneal liposarcoma. Am J Surg 2002184 (1): 56-57.

24. Farese $\mathbf{S}$, Palasciano N. A case of giant retroperitoneal liposarcoma. Chir Ital 2002; 54 (1): 95-98.

25. Azpiazu Arnaiz P, Muro Bidaurre I, De Frutos Gamero A et al. Retroperitoneal tumours. Retroperitoneal myxoid liposarcoma. Report of a new case. Arch Esp Urol 2000; 53 (2): 170-173.

26. Fernández-Ruiz M, Rodriguez-Gil Y, Guerra-Vales JM et al. Primary retroperitoneal liposarcoma: clinical and histological analysis of ten cases. Gastroenterol Hepatol 2010; 33 (5): 370-376.

27. Smrkolj S, Rakar S, Stolfa A, Kobal B. Giant pelvic retroperitoneal liposarcoma: case report. Eur J Gynaecol Oncol 2010; 31 (6): 705-708.
28. Susini T, Taddei G, Massi D, Massi G. Giant pelvic retroperitoneal liposarcoma. Obstet Gynecol 2000; 95 (6Pt2): 1002-1004.

29. Izumi H, Dowaki S, Matsuyama M et al. Retroperitoneal liposarcoma: a case report. Nippon Shokakibyo Gakkai Zasshi 2010; 107 (9): 1505-1512.

30. Ebbe M: A $6 \mathrm{~kg}$ retroperitoneal liposarcoma in a 42 -year-old woman. Case report. Scand J Urol Nephrol 1993; 27 (3): 409-412.

31. Tsang A, Nash JR, Fordham MV et al. The management of retroperitoneal liposarcoma with synchronous intra-duodenal sarcoma. Eur J Surg Oncol 2003, 29 (6): 515-518.

32. Inoue K, Higaki Y, Yoshida H. Giant retroperitoneal liposarcoma.Int J Urol 2005; 12 (2): 220-222.

33. Hsiao JC, Yang YC, Lin WC et al. Primary retroperitoneal liposarcoma mimicking ovarian cancer: a case report. Zhonghua Yi Xue Za Zhi (Taipei) 1998; 61 (5): 295-300.

34. Shoji S, Uchida T, Yamashita E et al. Retroperitoneal mixed-type liposarcoma detected by health examination. Hinyokika Kiyo 2009; 55 (9): 555-557.

35. Takahashi Y, Irisawa A, Bhutani MS et al. Two cases of retroperitoneal liposarcoma diagnosed using endoscopic ultrasound-guided fine nedele aspiration (EUS-FNA). Diagn Ther Endosc 2009; 2009: 673-694.

36. Funahashi Y, Kamihira $\mathbf{O}$, Isobe $\mathbf{Y}$ et al. Retroperitoneal liposarcoma: a case report. Hinyokika Kiyo 2006; 52 (3): 203-205.

37. Kurosaki Y, Tanaka YO, Itai Y. Well-differentiated liposarcoma of the retroperitoneum with a fat-fluid level: US, CT, and MR appearance. Eur Radiol 1998; 8 (3): 474-475.

38. Guzmán Martínez-Valls PL, Ferrero Doria R, López Alba J et al. Retroperitoneal liposarcoma.Apropos of 3 cases. Arch Esp Urol 1997; 50 (5): 529-531.

39. Dieckmann C, Habermann CR, Zornig C et al. Computerized tomography of retroperitoneal liposarcoma.Aktuelle Radiol 1997; 7 (1): 23-29.

40. Sato T, Nishimura G, Nonomura A, Miwa K. Int Surg 1999; 84 (2): $163-167$.

41. Song T, Shen J, Liang BL et al. Retroperitoneal liposarcoma: MR characteristics and pathological correlative analysis. Abdom Imaging 2007; 32 (5): 668-674.

42. Shioi Y, Hasegawa T, Otsuka $\mathbf{K}$ et al. Primary retroperitoneal spindle cell liposarcoma: pathological and immunohistochemical findings. Pathol Int 2010; 60 (6): 472-476.

43. Singer S, Antonescu CR, Riedel E, Brennan MF. Histologicsubtype and margin of resection predict pattern of recurrence and survival for retroperitoneal liposarcoma. Ann Surg 2003; 238 (3): 358-370.

44. Niedergethmann M, Hildenbrand R, Winkler M. Monstrous, retroperitoneal liposarcoma-a case report. Swiss Surg 2001; 7 (1): 32-35.

45. Farma R, Tirone G, Berlanda G et al. G Chir 2003, 24 (8-9): 305-308.

46. Fotiadis C, Zografos GN, Karatzas G et al. Recurrent liposarcomas of the abdomen and retroperitoneum: three case reports. Anticancer Res 2000; 20 (1B): 579-583.

47. Lauretti S, Cappa M, Emiliozzi P et al. Retroperitoneal liposarcoma. Minerva Chir 1998; 53 (1-2): 77-81.

48. Yoshida Y, Inoue K, Ohsako T et al. Weekly paclitaxel therapy is curative for patients with retroperitoneal liposarcoma. Gan To Kagaku Ryoho 2007; 34 (3): 465-467.

49. Yokoi M, Hosokawa K, Funaki H et al. Gan To Kagaku Ryoho 2009; 36 (12): 2114-2116.

50. Baratti D, Pennacchioli E, Kusamura $S$ et al. Peritoneal sarcomatosis: is there a subset of patients who may benefit from cytoreductive surgery and hyperthermic intraperitoneal chemotherapy? Ann Surg Oncol 2010; 17 (12): 3220-3228.

Received December 21, 2011. Accepted August 10, 2011. 